\title{
A new locus for autosomal recessive non-syndromal sensorineural hearing impairment (DFNB27) on chromosome 2q23-q31
}

\author{
LJ Pulleyn ${ }^{1}$, AP Jackson ${ }^{1,2}$, E Roberts $^{1}$, A Carridice $^{1}$, C Muxworthy $^{1}$, M Houseman $^{1}$, \\ LI Al-Gazali ${ }^{3}$, NJ Lench ${ }^{1}$, AF Markham ${ }^{1}$ and RF Mueller ${ }^{2}$
}

\begin{abstract}
${ }^{1}$ M olecular M edicine Unit, University of Leeds, St James's University Hospital; ${ }^{2}$ Department of Clinical Genetics, StJames's University Hospital, Leeds, UK; ${ }^{3}$ Department of Paediatrics, Faculty of Medicine, UAE University, Al Ain, United Arab Emirates
\end{abstract}

\begin{abstract}
Non-syndromic sensorineural deafness is an extremely genetically heterogeneous condition. We have used autozygosity mapping in a large consanguineous United Arab Emirate family to identify a novel locus for autosomal recessive non-syndromic sensorineural deafness, DFNB27, on chromosome 2q23-q31, with a maximum two-point lod score of 5.18 at $\theta=0$ for marker D2S2257. The DFNB27 locus extends over a $17 \mathrm{cM}$ region between D2S2157 and D2S2273, and may overlap the DFNA16 locus for dominantly inherited, fluctuating, progressive non-syndromal hearing loss. However, genotype data suggests that the locus is likely to be refined to between D2S326 and D2S2273 and thus distinct from the DFNA16 locus. European Journal of Human Genetics (2000) 8, 991-993.
\end{abstract}

Keywords: DFNB27; DFNA16; locus heterogeneity; chromosome 2q; homozygosity mapping; autozygosity mapping

\section{Introduction}

Non-syndromal sensorineural hearing impairment in humans is genetically heterogeneous showing autosomal recessive, autosomal dominant, $\mathrm{X}$-linked or mitochondrial modes of transmission. Autosomal recessive inheritance accounts for the majority (about $80 \%$ ) of cases, is highly heterogeneous, with 22 loci (DFNB1-18, 20, 21, 26 and 28) reported to date (Hereditary Hearing Loss Homepage). These developments in molecular genetics are rapidly leading to diagnostic tests which will become routine in identifying inherited causes of hearing impairment.

\section{Materials and methods}

We ascertained a large consanguineous Baluchi family from the United Arab Emirates with seven individuals with prelingual non-syndromal sensorineural hearing impairment in two sibships (Figure 1). The presence of complex con-

Correspondence: RF Mueller, Professor of Clinical Genetics, Dept of Clinical Genetics, St James's University Hospital, Beckett St,

Leeds, LS9 7TF, UK. Tel: +44 113206 5143; Fax: +44 113246 7090; E-mail: msjrfm@leeds.ac.uk

Received 17 May 2000; revised 24 July 2000; accepted 1 August 2000 sanguinity in the family permitted an autozygosity (homozygosity) mapping approach to carry out a genome search. ${ }^{1} \mathrm{~A}$ genomewide linkage screen was performed using the Weber microsatellite marker panel version 8 (Research Genetics, Huntsville, AL, USA), which comprised 386 fluorescently labelled primer pairs, with an average marker spacing of 10 CM. PCR amplification of microsatellite markers was carried out using the MWG Roboseq 4200 robot. The products were pooled and run on a $4.2 \%$ polyacrylamide gel at $3000 \mathrm{~V}$ for $2.5 \mathrm{~h}$ on an $\mathrm{ABI}$ Prism 377 sequencer. The $\mathrm{ABI}$ Prism Genescan and Genotyper 1.1.1 programs were used to analyse the gel images to derive allele sizes. Additional microsatellite markers were chosen for fine mapping on $2 q$ from the Généthon Linkage Map or the Genome Database. Distances between markers were calculated using the Marshfield Linkage Map. Linkage analysis was performed assuming a fully penetrant autosomal recessive mode of inheritance and a disease allele frequency of 0.004 . Two point analysis was performed using the MLINK component of the LINKAGE programs. $^{2,3}$ Marker allele frequencies were calculated by typing 34 controls from the same population, with a lower limit for allele frequencies set at 0.1 . 


\section{Results}

A genome search revealed a region of homozygosity on chromosome $2 \mathrm{q}$ in all the affected individuals in the consanguineous sibship (Figure 1). This area extends for an interval of $46 \mathrm{cM}$ between D2S156 and GATA30E06 (in individuals $\mathrm{VI}: 6, \mathrm{VI}: 7$, and $\mathrm{VI}: 10$, sibship 2, data not shown). Homozygosity was not seen for this interval in the unaffected siblings in this sibship. The haplotype from the homozygous region is carried by the father of the other sibship, $V: 1$, and is inherited by all his affected offspring.

Individuals $\mathrm{VI}: 1, \mathrm{VI}: 3$ and $\mathrm{VI}: 4$ also share the same maternal haplotype over the entire region, but $\mathrm{VI}: 5$ shares only the region distal to $\mathrm{D} 2 \mathrm{~S} 2157$ due to a recombination event between D2S2157 and D2S326. Therefore the minimum critical region for DFNB27 is a $17 \mathrm{cM}$ region between D2S2157 and D2S2273. Two point linkage analysis gives a maximum lod score of 5.18 at $\theta=0$ for marker D2S2257 (Table 1).

It is interesting to note that although $\mathrm{V}: 2$ is not known to share a common ancestor with the family, she has the same haplotype in common with her husband, and also the other parents, V:3 and V:4, for markers D2S2307, D2S2257 and
D2S148. Therefore, if she were unknowingly related, which is possible since the family originates from the same small village, there would be a region of homozygosity by descent shared by all seven affected individuals in the pedigree between markers D2S326 and D2S2273.

\section{Discussion}

The DFNB27 critical region overlaps with the critical region to which DFNA16 was recently mapped on 2q23-q24.3 in a family with fluctuating, progressive autosomal dominant nonsyndromal hearing loss. ${ }^{4}$ The DFNA16 locus maps between markers D2S2380 and D2S335.

There are two possible explanations for these findings. Firstly, the two deafness disorders mapping to DFNB27 and DFNA16 could be caused by mutations in the same gene which would map within the overlapping interval of the two loci, between markers D2S2157 and D2S335. This has been the case with other hearing impairment loci, for autosomal recessive and dominant inherited hearing impairment loci DFNB1 and DFNA3 mapping to $13 q 12,{ }^{5,6}$ as well as for DFNB2 and DFNA11 to $11 q 12.3-q 21,7,8$ with mutations

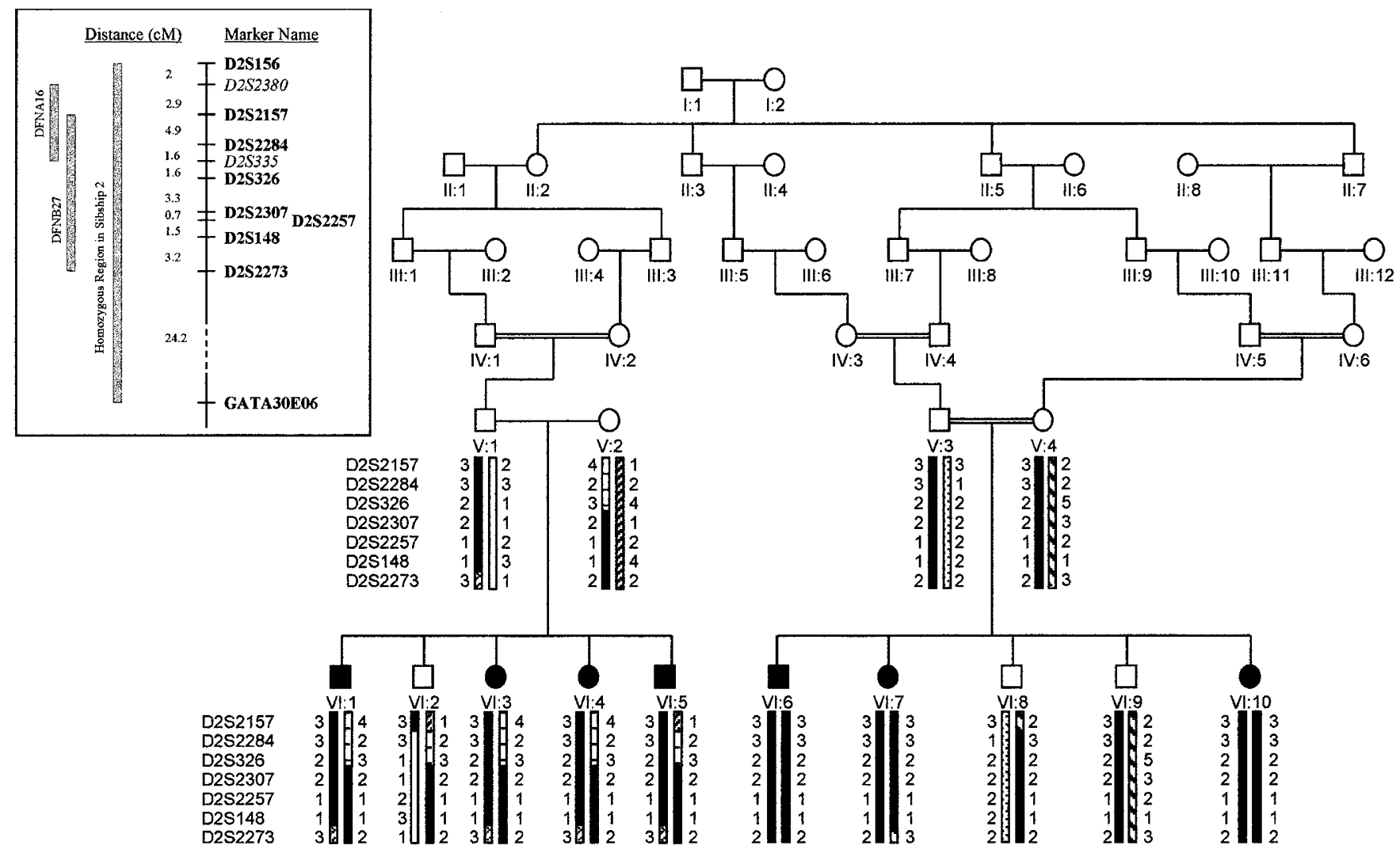

Figure 1 Haplotypes for seven markers from 2q23-31 defining the DFNB27 minimum critical region. Sibship 1, individuals VI:1-5; sibship 2, individuals Vl:6-10. The black haplotype bar indicates the likely high risk (ancestral) haplotype. In this diagram, V:2 is shown carrying part of this high risk haplotype, consistent with the possibility of being related to her husband, V:1. The insert shows a map of relevant polymorphic markers and critical regions. Markers genotyped in this study are in bold, and other relevant markers are shown in italic. 
Table 1 Two point lod scores

\begin{tabular}{llllllll}
\hline Marker & 0.0 & 0.01 & 0.05 & 0.1 & 0.2 & 0.3 & 0.4 \\
\hline D2S2157 & $-\infty$ & 2.14 & 2.47 & 2.30 & 1.64 & 0.90 & 0.28 \\
D2S2284 & 1.87 & 1.81 & 1.59 & 1.33 & 0.83 & 0.40 & 0.10 \\
D2S326 & 3.97 & 3.88 & 3.52 & 3.06 & 2.09 & 1.14 & 0.36 \\
D2S2307 & 3.39 & 3.31 & 2.97 & 2.54 & 1.70 & 0.91 & 0.27 \\
D2S2257 & 5.18 & 5.05 & 4.55 & 3.91 & 2.62 & 1.37 & 0.39 \\
D2S148 & 3.65 & 3.57 & 3.21 & 2.76 & 1.86 & 1.00 & 0.30 \\
D2S2273 & $-\infty$ & -0.88 & 0.02 & 0.32 & 0.41 & 0.28 & 0.10 \\
\hline
\end{tabular}

being identified GJB2 $2^{9,10}$ in the former and MYOVIIA ${ }^{11-13}$ in the latter. In addition, mutations in the TECTA gene have been shown to cause both autosomal dominant and recessive non-syndromal sensorineural hearing impairment. ${ }^{14,15}$

Alternatively, the two disorders could be caused by mutations in two different genes on $2 q$, as appears to be the situation on 1 p34 for DFNA2. ${ }^{16}$ Also on $11 q 23$, in addition to the TECTA gene, another locus responsible for inherited hearing impairment, DFNB24, has been mapped, with TECTA being excluded as the causative gene (Smith $R$, unpublished data, 2000, Hereditary Hearing Loss Homepage).

This second hypothesis would be supported if $\mathrm{V}: 2 \mathrm{did}$, in fact, share a common ancestor with $V: 1$, which would seem likely in view of their common origin and the high rate of consanguinity. The autozygous region between D2S326 and D2S2273 would then define a 9 cM critical region for DFNB27 that may be distinct from, and no longer overlap with DFNA16. Further genotyping within this region and/or the identification of further families with either autosomal dominant or recessive non-syndromal sensorineural hearing impairment mapping in the interval $2 q 23-q 31$ could help refine the critical regions and confirm whether the two loci are distinct.

The brain sodium-channel $\alpha$-subunit genes SCN1A, SCN2A1 and SCN3A, which map to the critical region, are potential candidate genes for both DFNA16 ${ }^{4}$ and DFNB27, as well as a more recently identified fourth isoform, SCN $2 \mathrm{~A} 2$ which is known to localise to $2 q 23-q 24 .{ }^{17}$ Identification of mutations in one or more of these genes, or other positional candidate genes, will determine whether DFNA16 and DFNB27 are allelic.

\section{Acknowledgements}

This work was supported by funding from the National Lotteries Charities Board through Defeating Deafness, the European
Community through Framework $\mathrm{V}$, the Wellcome Trust, the Medical Research Council, Action Research and the West Riding Medical Research Trust.

\section{References}

1 Lander ES, Botstein D: Homozygosity mapping: A way to map human recessive traits with the DNA of inbred children. Science 1994; 265: 2049-2054.

2 Cottingham RW Jr, Idury RM, Schaffer AA: Faster sequential genetic linkage computations. Am J Hum Genet 1993; 53: 252-263.

3 Schaffer AA, Gupta SK, Shriram K, Cottingham RW Jr: Avoiding recomputation in linkage analysis. Hum Hered 1994; 44: 225-237.

4 Fukushima K, Kasai N, Ueki $Y$ et al: A gene for fluctuating, progressive autosomal dominant nonsyndromic hearing loss, DFNA16, maps to chromosome 2q23-24.3. Am J Hum Genet 1999; 65: $141-150$.

5 Guilford P, Ben Arab S, Blanchard S et al: A non-syndrome form of neurosensory, recessive deafness maps to the pericentromeric region of chromosome 13q. Nat Genet 1994; 6: 24-28.

6 Chaib H, Lina-Granade $G$, Guilford $P$ et al: A gene responsible for a dominant form of neurosensory non-syndromic deafness maps to the NSRD1 recessive deafness gene interval. Hum Mol Genet 1994; 3: 2219-2222.

7 Guilford $\mathrm{P}$, Ayadi $\mathrm{H}$, Blanchard $\mathrm{S}$ et al: A human gene responsible for neurosensory, non-syndromic recessive deafness is a candidate homologue of the mouse sh-1gene. Hum Mol Genet 1994; 3: 989-993.

8 Tamagawa $\mathrm{Y}$, Kitamura $\mathrm{K}$, Ishida $\mathrm{T}$ et al: A gene for a dominant form of non-syndromic sensorineural deafness (DFNA11) maps within the region containing the DFNB2 recessive deafness gene. Hum Mol Genet 1996; 5: 849-852.

9 Kelsell DP, Dunlop J, Stevens HP et al: Connexin 26 mutations in hereditary non-syndromic sensorineural deafness. Nature 1997; 387: 80-83.

10 Denoyelle F, Lina-Granade G, Plauchu H et al: Connexin 26 gene linked to a dominant deafness. Nature 1998; 393: 319-320.

11 Liu XZ, Walsh J, Mburu P et al: Mutations in the myosin VIIA gene cause non-syndromic recessive deafness. Nat Genet 1997; 16: 188-190.

12 Liu XZ, Walsh J, Tamagawa $Y$ et al: Autosomal dominant nonsyndromic deafness caused by a mutation in the myosin VIIA gene. Nat Genet 1997; 17: 268-269.

13 Weil D, Kussel $\mathrm{P}$, Blanchard $\mathrm{S}$ et al: The autosomal recessive isolated deafness, DFNB2, and the Usher 1B syndrome are allelic defects of the myosin-VIIA gene. Nat Genet 1997; 16: 191-193.

14 Verhoeven $K$, Van Laer L, Kirschhofer $\mathrm{K}$ et al: Mutations in the alpha-tectorin gene cause autosomal dominant non-syndromic hearing impairment. Nat Genet 1998; 19: 60-62.

15 Mustapha M, Weil D, Chardenoux S et al: An al pha-tectorin gene defect causes a newly identified autosomal recessive form of sensorineural pre-lingual non-syndromic deafness, DFNB2. Hum Mol Genet 1999; 8: 409-412.

16 Van Hauwe P, Coucke PJ, Declau F et al: Deafness linked to DFNA2: one locus but how many genes? Nat Genet 1999; 21: 263.

17 Baulac S, Gourfinkel-An I, Picard F et al: A second locus for familial generalized epilepsy with febrile seizures plus maps to chromosome 2q21-q33. Am J Hum Genet 1999; 65: 1078-1085. 